\title{
Effects of water discharge and sediment load on evolution of modern Yellow River Delta, China, over the period from 1976 to 2009
}

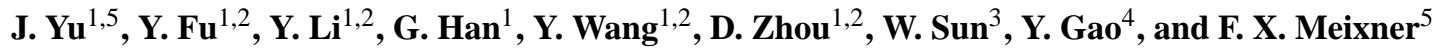 \\ ${ }^{1}$ Key Laboratory of Coastal Zone Environmental Processes, Laboratory of Coastal Wetland Ecology, \\ Yantai Institute of Coastal Zone Research, Chinese Academy of Sciences, Yantai 264003, China \\ ${ }^{2}$ Graduate University of Chinese Academy of Sciences, Beijing 100049, China \\ ${ }^{3}$ Key Laboratory of Isotope Geochronology and Geochemistry, Guangzhou Institute of Geochemistry, \\ Chinese Academy of Sciences, Wushan, Guangzhou, 510640, China \\ ${ }^{4}$ Department of Earth and Atmospheric Sciences, University of Houston, Houston, TX 77204, USA \\ ${ }^{5}$ Biogeochemistry Department, Max Planck Institute for Chemistry, P.O. Box 3060, 55020 Mainz, Germany
}

Received: 7 March 2011 - Published in Biogeosciences Discuss.: 26 April 2011

Revised: 14 August 2011 - Accepted: 27 August 2011 - Published: 5 September 2011

\begin{abstract}
The Yellow River, which is the second largest river in China, is regarded as the world's largest contributor of fluvial sediment load to the ocean. In recent decades, the dramatic reduction in water discharge and sediment load due to climate change and human activities in the drainage basin has greatly constrained the evolution process of Yellow River delta. We highlight how runoff and sediment load discharged into sea affected extension of shoreline length and area of modern Yellow River delta during 1976-2009 based on remote sensing interpretation and long-term monitoring data in hydrological station. Average runoff of $207.47 \times 10^{8} \mathrm{~m}^{3} \mathrm{yr}^{-1}$ and average sediment load of $4.63 \times 10^{8} \mathrm{~m}^{3} \mathrm{yr}^{-1}$ were discharged into the sea from 1976 to 2008 . The annual runoff reduced by $\sim 59.7 \%$ in 1990 2002 and annual sediment load reduction up to $\sim 72.1 \%$ in 2003-2008. Both shoreline length and area of Yellow River Delta extended overall in the studied period, but with decreasing rates in accordance with changes of runoff and sediment load. High increasing rate of shoreline length of $\sim 3.63 \mathrm{~km} \mathrm{yr}^{-1}$ and quick area extension of $\sim 16.26 \mathrm{~km}^{2} \mathrm{yr}^{-1}$ were observed in 1976-1985. Since 1996 however, the average increase rate of shoreline length and area decreased to $\sim 0.80 \mathrm{~km} \mathrm{yr}^{-1}$ and $\sim 3.94 \mathrm{~km}^{2} \mathrm{yr}^{-1}$, respectively. In addition, the fluctuated changes of shoreline and area were great and the net negative increase of land area was occurred during this period. There exist significant exponential rela-
\end{abstract}

Correspondence to: J. Yu

(junbao.yu@gmail.com) tionships between the accumulated sediment load and extensions of shoreline length and the area during the evolution of the modern Yellow River Delta. Our results indicate that the evolution of shoreline and change of area of the Yellow River Delta are directly affected by the dramatic reduction of runoff and sediment load, which are much close related human being activities in Yellow River drainage basin in recent decades.

\section{Introduction}

The river's water discharge and sediment load flow into the sea are dominant factors that control the coastal delta evolution, i.e. the landform shape of river mouth, the beach process and the coastal zone ecological environment (Chen et al., 2001a; Qian et al., 1993). The impacts of sediment transport and deposit in world large rivers on the delta-coast morphology have been the major research topics in the past few decades (Chen et al., 2001b; Milliman and Meade, 1983; Milliman and Syvitski, 1992), and the processes of water discharge and sediment load into the sea have become a global issue of common concern (Bobrovitskaya et al., 2003; Peng and Chen, 2010; Vorosmarty et al., 2003; Walling and Fang, 2003). The Yellow River, which is the second largest river in the China, originates from the Qinghai-Tibet Plateau, flows eastwards through the Loess Plateau and North China Plain, and disembogues itself into the Bohai Sea at Kenli in Shandong Province (see Fig. 1 in Wang et al., 2006), with a basin area of $752433 \mathrm{~km}^{2}$ and a mainstream length extending

Published by Copernicus Publications on behalf of the European Geosciences Union. 


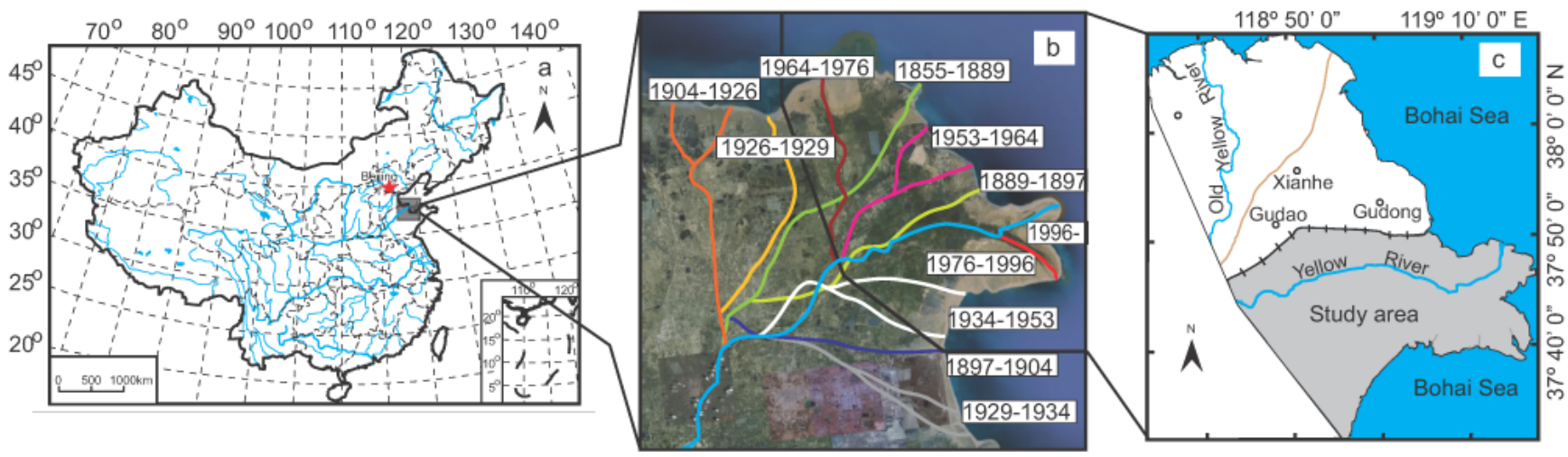

Fig. 1. Location map of modern Yellow River Delta (a), history changes of river channel (b, modified after Xue, 1993) and study area (c).

$5464 \mathrm{~km}$ (Qian et al., 1993). It is regarded as largest contributor of fluvial sediment load to the ocean in the world (Wang and Aubrey, 1987). In recent decades, the changes of the water discharge and sediment load of the Yellow River closely associated with intensifying human activity and climate change have been widely noticed (Liu et al., 2009; Chen, 1997; Fan et al., 2006, 2007; Peng and Chen, 2010; Wang et al., 2006, 2007). On the Yellow River basin, except for the water supply by the melted ice-cover on the Qinghai-Tibet Plateau, precipitation is the major source for river runoff and controls the drought-flood cycles of the river. The average precipitation in the 1990s was about $8.8 \%$ less than that in the 1950s (Peng and Chen, 2010). Human activities, e.g. the construction of reservoirs and dams, have played a critical role on the decrease of water discharge and sediment load into the sea. Before being influenced by human disturbances, the sediment load delivered into the sea reached 1.08-1.2 $\times 10^{9} \mathrm{t} \mathrm{yr}^{-1}$ (Milliman and Meade, 1983; Qian and Zhou, 1965), which accounts for $6 \%$ of the global rivers sediment load into the sea (Milliman and Syvitski, 1992). However, more recent data in period of 1990-2005 and 20002005 show that the annual sediment load reaching the sea is only $0.3 \times 10^{9} \mathrm{tyr}^{-1}$ (Liu et al., 2010) and $0.15 \times 10^{9} \mathrm{tyr}^{-1}$ (Wang et al., 2007), respectively.

Previous studies related to this topic mainly focused on hydraulic characteristics (Cui et al., 2009; Ding and Pan, 2007; Miao et al., 2010; Qiao et al., 2010), the sediment transportation (Cai et al., 2003; Li et al., 2010; Peng and Chen, 2009; Wang et al., 2008), wetland landscape (Li et al., 2009; Yang et al., 2008; Zong et al., 2009) of Yellow River Delta, as well as water consumption and the considered variations in regional precipitation to be slight fluctuations (Peng and Chen, 2010; Xu et al., 2004). Less attention has been paid on the detailed relation of water discharge and sediment load and evolution of Yellow River Delta. Peng (2010) provided an overview of the decreasing Yellow River water discharge during the past $50 \mathrm{yr}$ with reference to natural and anthropogenic impacts. Wang et al. (2008) investigated the contributions of climate change and human activities to the decreases in sediment load. The connections between water discharge, sediment load and evolution of Yellow River Delta has not yet been extensively investigated. In this study, we present the evolution processes of modern Yellow River Delta since 1976, which formed from the latest change of watercourse (Qinshuigou), with reference to precipitation, runoff and sediment discharge impacts, revealing the evolution mechanism of modern Yellow River Delta.

\section{Material and method}

\subsection{Region description}

The present Yellow River Delta is located in middle of eastern China, Shandong Province, as shown in Fig. 1a. Yellow River Delta was formed by functions of alluvium and siltation. When Yellow River flowed through the Loess Plateau, large amounts of sediment joined into water. Because of sea backwater, the flow rate of river water became slow and large proportion of sediment in water was deposited quickly at estuary. Dramatic sediment accumulation on the delta-coast has caused the large-scale avulsion of the Yellow River channel in the last few thousand years (Wang and Liang, 2000). The Yellow River has changed its major watercourse (about $600 \mathrm{~km}$ from the river mouth) 26 times in the last $2200 \mathrm{yr}$ based on record of "Outline History of China Water Resources". From 1855 to 1976 , it changed its delta channel (about $100 \mathrm{~km}$ from the mouth) 9 times and the river mouth had varied over a range of $100 \mathrm{~km}$ from its present position (Fig. 1b). The present channel (Qingshuigou channel), which resulted from artificial geo-engineering in 1976 and a minor shift of the mouth channel occurred in 1996, is the current prime outlet to the sea (Fig. 2b). Therefore, the study area is completely new-born land which has been created by rapid sediment deposition in past $35 \mathrm{yr}$ (Fig. 1c).

The Yellow River Delta is a temperate semi-humid continental monsoon climate. There is no obvious climate difference between northern and southern parts in the region. 
Average annual sunshine hours are $2590-2830 \mathrm{~h}$, average annual temperature $11.7-12.8^{\circ} \mathrm{C}$. The frost-free period is $206 \mathrm{~d}$ in a year and annual accumulated temperature of $\geq 10^{\circ} \mathrm{C}$ is $4300^{\circ} \mathrm{C}$. The average annual precipitation is $530-630 \mathrm{~mm}$, which of $70 \%$ is in the summer, and the average annual evaporation is $1900-2400 \mathrm{~mm}$ (Song et al., 2008). The soil is typical saline alluvial soil (Fluvisols, FAO) developed on loess material of the Quaternary period, which was carried by water from the Loess Plateau. The soil characteristics in new-born land have low nutrients and high salinity (Yu et al., 2010). The natural vegetation is salt meadow with more than $85 \%$ species are salt tolerant plants and aquatic plants. The plant community composition is simple with small number of constructive species. The predominant species in the region are Suaeda heteropter Kitag, Phragmites australis, Tamarix chinensis Lour., Aeluropus sinenis and Imperata cylindrica (Linn.) Beauv (He et al., 2007).

\subsection{Data and methods}

Landsat Multi-Spectrum Scanner (MSS) and Thematic Mapper (TM) images of 1976-1977, 1979, 1981, 1984-1987, 1989, 1991-2001, 2004, 2006 and 2009 were used to study the change of shoreline and land area in the study region since 1976. All the images were corrected for removing atmospheric effects by subtracting the radiance of a "dark pixel" within each band image (Lavery et al., 1993), and were geo-referenced and rectified following the procedure by Serra et al. (2003). The information extraction method of shoreline is important in the study because the border line of land and water is impacted greatly by tides for a gentle beach slope $(0.2-0.7 \%$ o $)$ in the Yellow River Delta. The methods of low water line (Yang et al., 1999), average high tide line (Fan et al., 2009; Huang and Fan, 2004) and tide and the slope correction (Huang and Li, 1994) have been applied to extract shoreline information of the Yellow River Delta in previous studies. In this study, the average high tide line method, which reference to Fan et al. (2009) was used to extract shoreline information of the Yellow River Delta because the method is a practical way to meet the required accuracy of the macroscopic analysis.

The data sets (1976-2008) of runoff and sediment load (Lijin Hydrological Station, which is a most downstream hydrological station in Yellow River, is located at $118^{\circ} 18^{\prime} \mathrm{E}$, $37^{\circ} 31^{\prime} \mathrm{N}$, from the estuary month $104 \mathrm{~km}$.) used in this paper are obtained from the Yellow River Water Conservancy Commission and the River Sediment Bulletin of China, which were published by the Ministry of Hydrology, China, respectively. The data (1976-2008) of regional precipitation are got from the Water Source Bulletin of China and the River Sediment Bulletin of China. Linear regression analysis was used for studying the change trends of runoff and sediment discharge at Lijin Hydrological Station from 1976 to 2008 and the change of shoreline length and area of Yellow River Delta from 1976-2009, non-linear regression analysis for relation of shoreline length and area of the Yellow River Delta and accumulative runoff and sediment discharge at the Lijin Hydrological Station, respectively. The relationship of runoff and sediment discharge was analyzed by the correlation analysis. The software of SPSS12.0 (Lead Technologies, inc. USA) and Sigmaplot9.0 (Systat Software Inc., San Jose, CA, USA) was used for statistical analysis and mapping, respectively.

\section{Results and discussion}

\subsection{Water supply and sediment discharge of the Yellow River}

With a characteristics of great inter-annual variations and synchronous fluctuations of runoff, sediment load and precipitation in an alternation in flood period and drought period, the annual runoff and annual sediment load from the Yellow River discharged to sea showed a downward trend with time overall (Fig. 2a, b, c). From 1976 to 2008, an average runoff of $207.47 \times 10^{8} \mathrm{~m}^{3} \mathrm{yr}^{-1}$ and an average sediment load of $4.63 \times 10^{8} \mathrm{~m}^{3} \mathrm{yr}^{-1}$ have been discharged into sea. The peaks of annual runoff and sediment load were $496.0 \times 10^{8} \mathrm{~m}^{3}$ in 1983 and $11.5 \times 10^{8} \mathrm{t}$ in 1981 , respectively, and the minimum values of both annual runoff $\left(18.6 \times 10^{8} \mathrm{~m}^{3}\right)$ and sediment load $\left(0.16 \times 10^{8} \mathrm{t}\right)$ appeared in 1997. The maximum of annual runoff and sediment load were about 26 times and 70 times of the minimum values, respectively. The variation coefficients of annual runoff and sediment load were $58.0 \%$ and $73.8 \%$, respectively, indicating the inter-annual variations of runoff and sediment were great during studied period.

The runoff and sediment discharges can be divided into three stages, i.e. before 1990, 1990-2002 and after 2002. Prior to 1990 , the Yellow River have a mean water discharge of $296.44 \times 10^{8} \mathrm{~m}^{3} \mathrm{yr}^{-1}$ and a sediment load of $7.14 \times 10^{8} \mathrm{tyr}^{-1}$, which is similar to previous studies (Fan et al. 2006). During period of 1990-2002, they had reduced to $119.56 \times 10^{8} \mathrm{~m}^{3} \mathrm{yr}^{-1}$ and $3.14 \times 10^{8} \mathrm{t} \mathrm{yr}^{-1}$, respectively, which are equivalent to $59.7 \%$ and $56.0 \%$ reduction, respectively. After 2002, the mean water discharge have increased to $189.97 \times 10^{8} \mathrm{~m}^{3} \mathrm{yr}^{-1}$ ( $\sim 35.9 \%$ reduction), but the mean sediment load further reduced to $1.99 \times 10^{8} \mathrm{tyr}^{-1}$ ( $\sim 72.1 \%$ reduction). The result is much close to a recent estimated value of $1.5 \times 10^{8} \mathrm{tyr}^{-1}$ for sediment load (Wang et al., 2007). Hydrological records of the Lijin Hydrological Station display that the total seasonal dry-up events of the Yellow River channel since 1972 is 1035 days, with 1015 days occurred in the 1990s. The most serious dry-up of the Yellow River happed in 1997, with 13 dry-up events and a total duration of 226 days within 11 months and dry-up channel of about $704 \mathrm{~km}$ (Fig. 2d), because rainfall and runoff in the Yellow River basin was much below normal (Fig. 2a, c). The phenomenon of dry-up has not occurred in downstream of the Yellow River any more since the water resource allocation in 

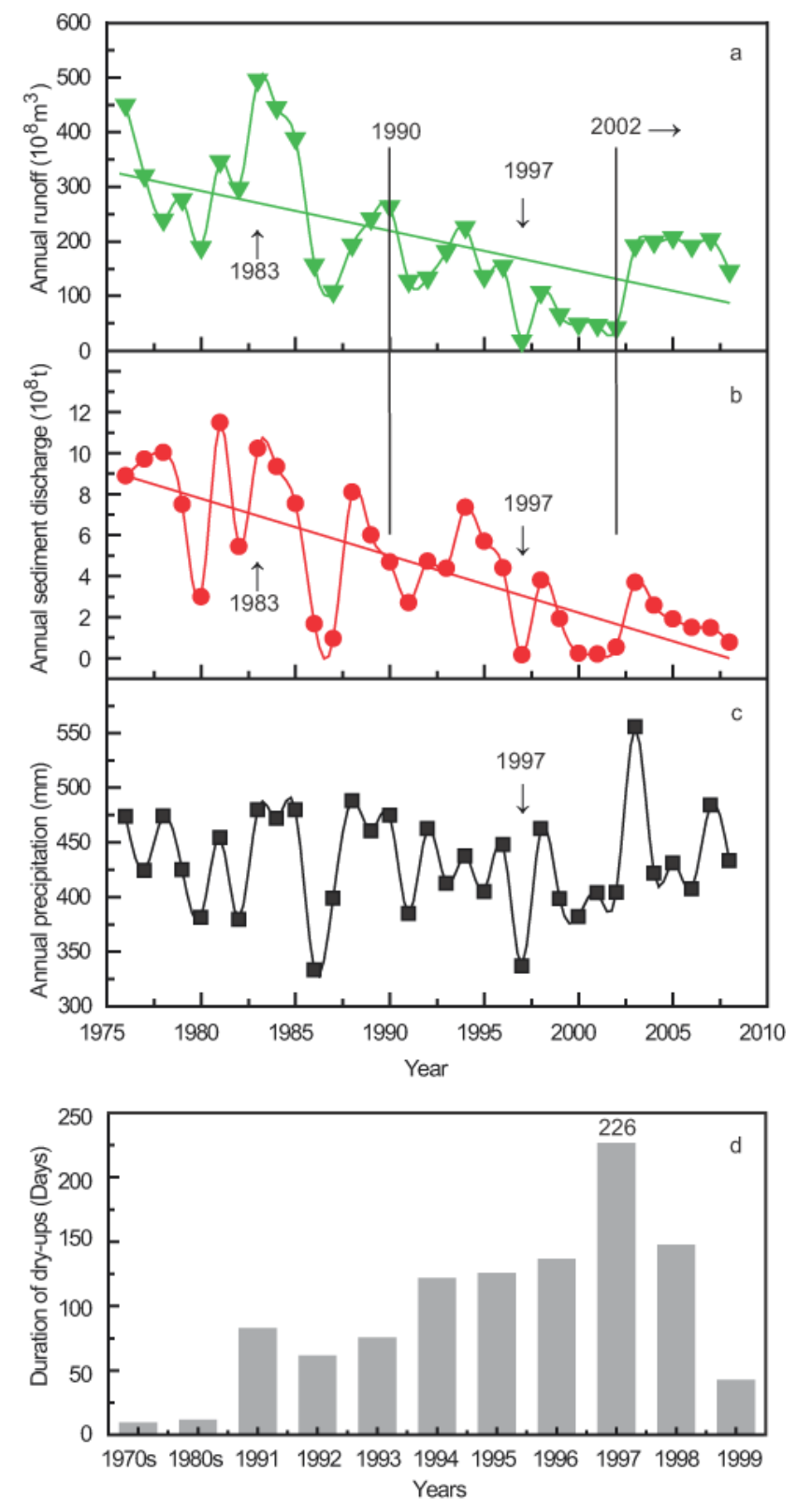

Fig. 2. Annual runoff (a) and sediment (b) at Lijin Hydrological Station, the annual precipitation (c) of the Yellow River Basin and seasonal drying ups (d) of Yellow River from 1976 to 2008.

the Yellow River Basin was planed to regulate through $\mathrm{Xi}$ aolangdi reservoir starting in 1999 (Fig. 2d). From 2002 to 2009, 9 times of water and sediment regulations were carried out, thus the water and sediment environment was improved. The runoffs of the Yellow River in 2005 and 2007 into the sea were more than $200 \times 10^{8} \mathrm{~m}^{3}$, which closed to average annual runoff, and the sediment discharge increased to $3.69 \times 10^{8} \mathrm{t}$ in 2003 . However, even though a certain annual runoff was maintained in the river in the succeeding years, the annual sediment load decreased gradually because of sed- iment retention of Xiaolangdi reservoir (Fig. 2a, b). Besides climate change (Peng and Chen, 2009; Wang et al., 2006), human activities including soil and water conservation practices, water diversion and water conservancy project are the main causes for decrease and inter-annual variations of water discharge and sediment load into the sea. The by-stage dry-up and reduction of runoff are mainly caused by increase of water diversion quantity in the Yellow River basin contributes (Ding and Pan, 2007). The water diversion quantity in 1980s and 1990s is $\sim 300 \times 10^{8} \mathrm{~m}^{3}$, which is more than half of average multi-year natural runoff of the Yellow River (Liu and Cheng, 2000). About $85 \%$ of total water diversion was used for agricultural irrigation (Xu and Sun, 2003). Due to the construction of soil and water conservation in the mid and upstream area of the Yellow River, i.e. the soil erosion controlled area of $78000 \mathrm{~km}^{2}$ and 9399.8 ha forest and grassland of soil and water conservation in the Loess Plateau area were set up during 2000-2005, the soil erosion in the basin was weakened and sediment in water was reduced obviously (Ding and Pan, 2007; Peng and Chen, 2009). Water conservancy project in the Yellow River not only regulates the water and sediment from upstream, but affects the evolution of river channel in middle and downstream and sediment transport capacity in the river (Peng and Chen, 2009). Up to 2004, more than 3380 reservoirs including 12 large scale ones were built in the Yellow River basin. The total storage capacity of those was $563 \times 10^{8} \mathrm{~m}^{3}$, equal to $82 \%$ of average multi-year natural runoff monitored in the Lijin Hydrological Station (Huang and Li, 2004). A recent study showed that the average annual reduction of water discharge and sediment load by means of water-soil conservation practices were $2.02 \times 10^{9} \mathrm{~m}^{3}$ and $3.41 \times 10^{8} \mathrm{t}$, respectively, and the average annual volume by water abstraction for industry and agriculture were $2.52 \times 10^{10} \mathrm{~m}^{3}$ and $2.42 \times 10^{8} \mathrm{t}$, respectively, from 1950 to 2005 . The average sediment trapped by Sanmenxia Reservoir was $1.45 \times 10^{8} \mathrm{t}$ from 1960 to 2007 , and the average sediment retention of the Xiaolangdi Reservoir was $2.398 \times 10^{8} \mathrm{t}$ from 1997 to 2007 (Peng and Chen, 2010). Other study declared that the decrease in precipitation is responsible for $30 \%$ of the decrease in sediment load at estuary of the Yellow River Delta, while the remaining $70 \%$ is ascribed to human activities in the river basin, of which soil conservation practices contribute $40 \%$ to the total decrease. Sediment retention within reservoirs and operation of reservoirs in the upper reaches accounts for $20 \%$ and $10 \%$ of the total sediment load decrease, respectively (Wang et al., 2007). Comparing to data of 1976-1985, we estimate that the decrease in climate change (precipitation) is responsible for $15-16 \%$ of the decrease in runoff and sediment load at estuary of the Yellow River Delta from 1986-2009, the remaining $84-85 \%$ is for human activities in the river basin.

In general, synchronous fluctuations of precipitation, runoff and sediment load occurred (Fig. 2a, b, c). During period of 1976-2008, the significant relations of precipitation of the Yellow River basin and runoff and the sediment 

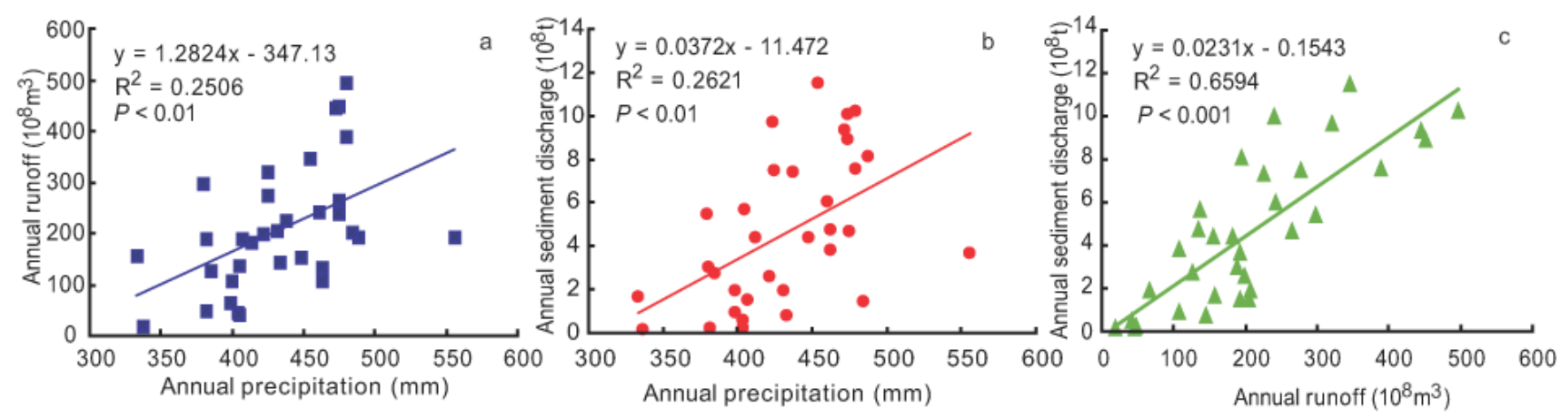

Fig. 3. Relationships of precipitation and runoff (a), precipitation and sediment (b) and runoff and sediment discharge (c) in Yellow River Delta in 1976-2008.

load discharged into sea from the Lijin Hydrological Station were observed (Fig. 3a, b). The precipitation, runoff and sediment load in 1980 were $381.2 \mathrm{~mm}, 189 \times 10^{8} \mathrm{~m}^{3}$ and $3.07 \times 10^{8} \mathrm{t}$, respectively. The runoff and sediment load increased to $346 \times 10^{8} \mathrm{~m}^{3}$ and $11.50 \times 10^{8} \mathrm{t}$, respectively, with precipitation of the Yellow River basin increased to $454.5 \mathrm{~mm}$ in 1981. Then in 1982, the precipitation reduced to $379.5 \mathrm{~mm}$, the runoff and sediment discharge also reduced to $297 \times 10^{8} \mathrm{~m}^{3}$ and $5.44 \times 10^{8} \mathrm{t}$, respectively. The results indicated that inter-annual fluctuation of precipitation was the most important reason for changes of runoff and sediment load discharged into sea. Because the runoff is interactive product of precipitation and land surface, and also a carrier for sediment transportation in the Yellow River, synchronization of rainfall, runoff and sediment load is maintained in the river system (Peng and Chen, 2009). Regression analysis result also showed that there was a significant linear positive relationship between runoff and sediment load (Fig. 3c).

\subsection{The revolution of shoreline and area of the Yellow River Delta}

The Qingshuigou channel extends into the sea for over $60 \mathrm{~km}$, and the shape of the Yellow River Delta with beakshaped river mouth has formed gradually since the river shifted to the channel in 1976. The river mouths of Qingshuigou and Qingbacha were formed by sediment deposit during periods of 1976-1995 and 1996-present, respectively (Fig. 4). From 1976 to 2009, both shoreline length and area of the Yellow River Delta were increasing overall, but the increase rate was decreasing step by step (Fig. 5). The net increase of delta shoreline length was $\sim 61.64 \mathrm{~km}$ with annual increase of $\sim 1.81 \mathrm{~km}$, and net extension of area was $\sim 309.81 \mathrm{~km}^{2}$ with rate of $\sim 9.11 \mathrm{~km}^{2} \mathrm{yr}^{-1}$ within $34 \mathrm{yr}$. The net shoreline length and area of the Yellow River Delta increased $50.18 \mathrm{~km}$ and $225.89 \mathrm{~km}^{2}$ during 1976-1995, respectively, and those extended $11.95 \mathrm{~km}$ and $96.6 \mathrm{~km}^{2}$ in the duration of 1996-2009, respectively.
According to the trend of shoreline and area changes, the evolution of the Yellow River Delta in the studied region can be divided into three stages, i.e. quick extension stage (1976-1985), stable extension stage (1986-1995) and slow and fluctuated extension stage (1996-2009) (Fig. 5a, b). A high rate of shoreline length increase of $\sim 3.63 \mathrm{~km} \mathrm{yr}^{-1}$ and a quick area extension of $\sim 16.26 \mathrm{~km}^{2} \mathrm{yr}^{-1}$ were observed during the period of 1976-1985. The Qingshuigou channel mouth had been seriously silted and many small branch channels and sand bars separating the channels emerged (Fan et al., 2006). Compared with prior stage, the increase rate of shoreline length $\left(2.13 \mathrm{~km} \mathrm{yr}^{-1}\right)$ and area $\left(9.79 \mathrm{~km}^{2} \mathrm{yr}^{-1}\right)$ were relative low and stable from 1986 to 1995 . In the meantime, oil production in the Yellow River Delta grew quickly and required the stabilization of the river rather than another shift of the channel. In July 1996, the new artificial channel diversion for the needs of oil field exploitation provided the Qingbacha distributary at the river mouth tip (Fig. 4). Since then, the shoreline started to extend at Qingbacha sand tip and retreat by erosion quickly at the old Qingshuigou sand tip because the sediment supply was cut off there (Fig. 4). In 2006, the flood carried a huge amount of sediment to the new river mouth and created $\sim 85 \mathrm{~km}^{2}$ of land, meantime $\sim 35 \mathrm{~km}^{2}$ land at old sand tip lost. Even at Qingbacha sand tip, both shoreline extension and retreat existed at same time by comparing shoreline of 2009 with 2006 and 2004 (Fig. 4). A previous study found that the new river mouth area was silted up by $14 \mathrm{~m}$ and the old river mouth area was eroded by $5 \mathrm{~m}$ (Wang and Liang, 2000). The average increases rate of shoreline length and area in 1996-2008 were only $\sim 0.80 \mathrm{~km} \mathrm{yr}^{-1}$ and $\sim 3.94 \mathrm{~km}^{2} \mathrm{yr}^{-1}$, which were about $22.2-37.9 \%$ and $24.3-40.3 \%$ of those in pervious stages of 1976-1985 and 1986-1995, respectively. In addition, the fluctuated changes of shoreline and area were great during the period (Fig. 5a, b). The net negative increases of land area occurred in 1997, 2000, 2001 and 2009. Our results indicate that the rapid stretch of Yellow River Delta has been past and the net negative extension of land area should be appeared frequently within future decade because of heavy human being activities in river basin. 


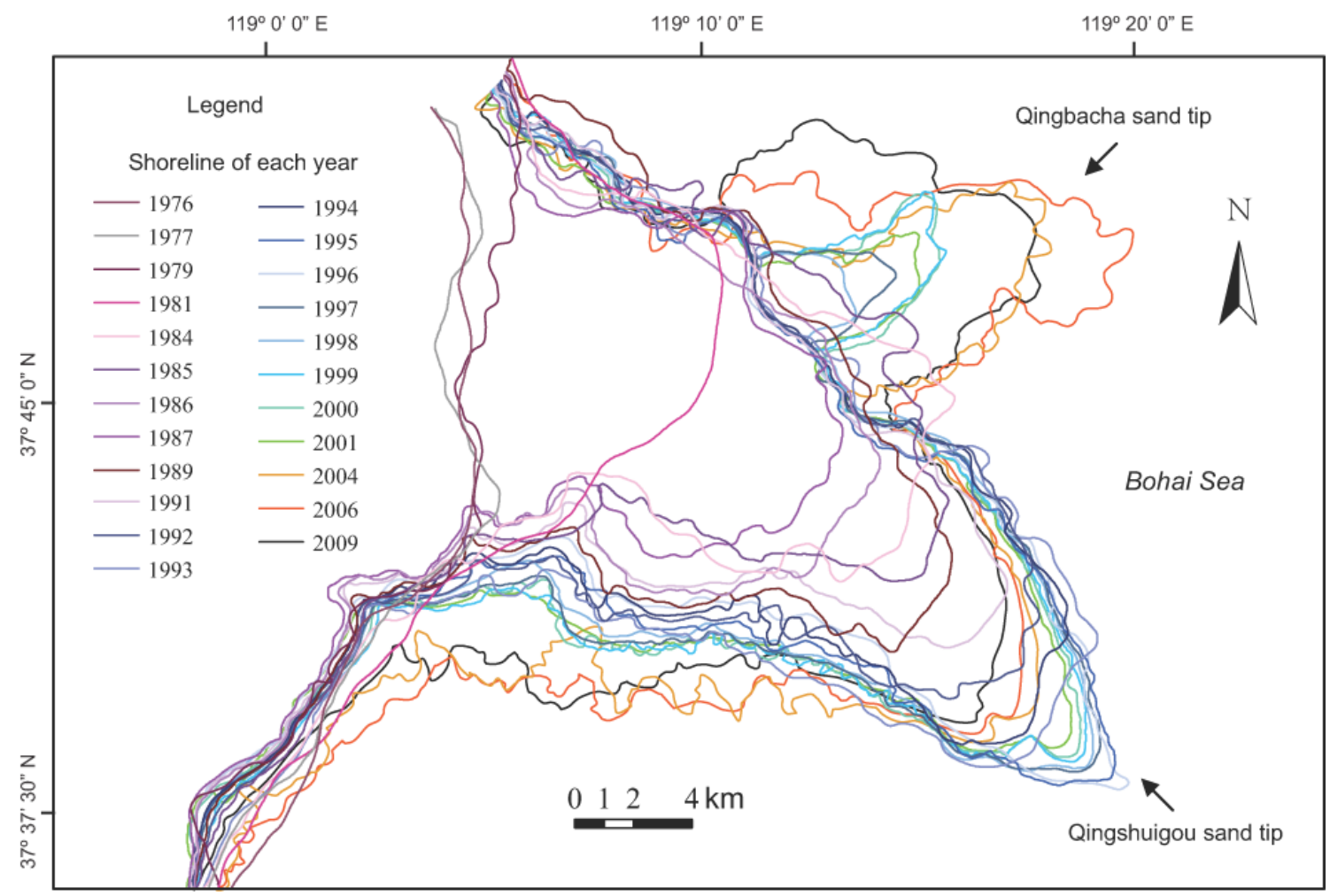

Fig. 4. Evolution processes of the Yellow River Delta from 1976 to 2009.

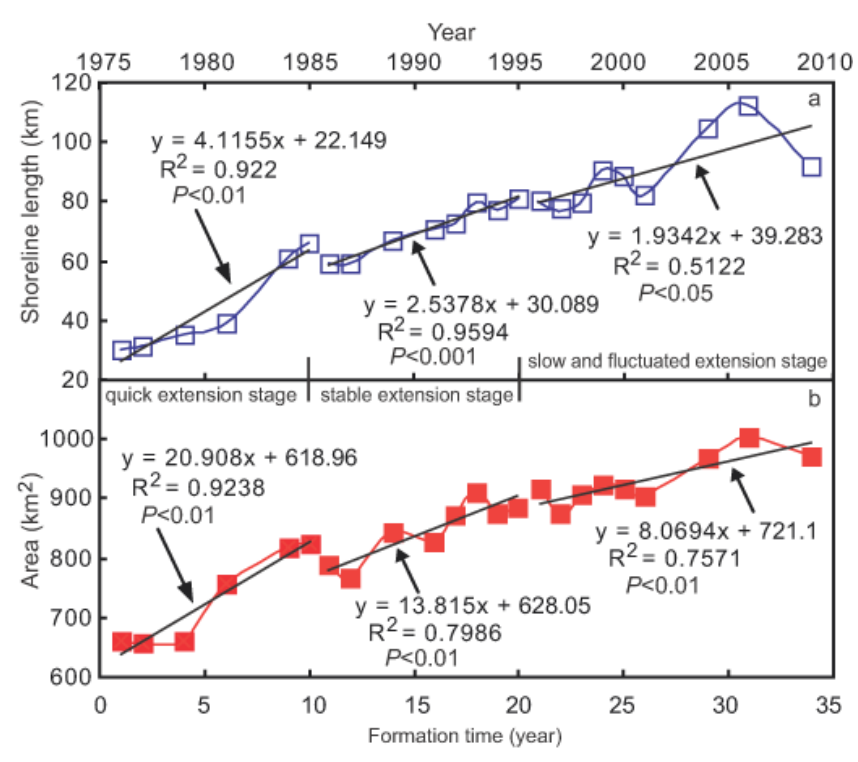

Fig. 5. The variations of shoreline length (a) and area (b) of the Yellow River Delta since 1976.

\subsection{The relation of accumulated sediment load and evolution of the Yellow River Delta}

There were close positive relationships between land creation rate and accumulated discharges of sediment $(R=0.96, p<$ $0.01)$ and runoff $(R=0.95, p<0.01)$ in the Yellow River Delta, and both the changes over time kept synchronization. The data of the Lijin Hydrological Station showed that the sediment load and water discharge of the Yellow River in 1976-1985 were $\sim 8.33 \times 10^{8} \mathrm{tyr}^{-1}$ and $\sim 344.86 \times$ $10^{8} \mathrm{~m}^{3} \mathrm{yr}^{-1}$, corresponding to rapid stretch of the estuary sand tip to the sea with the average annual shoreline length and area extending of $\sim 3.63 \mathrm{~km}$ and $\sim 16.26 \mathrm{~km}^{2}$, respectively (Figs. 6a, b and 4). In the duration of 1986-1995, the sediment load and runoff decreased to $4.24 \times 10^{8} \mathrm{t} \mathrm{yr}^{-1}$ and $177.18 \times 10^{8} \mathrm{~m}^{3} \mathrm{yr}^{-1}$, the land extension rate was dropped by $\sim 41 \%$ of that in previous stage. The average increases rate of shoreline length and area were only $\sim 2.13 \mathrm{~km} \mathrm{yr}^{-1}$ and $\sim 9.79 \mathrm{~km}^{2} \mathrm{yr}^{-1}$. Since 1996, the Yellow River entered into dry period and continued drying up year after year (Fig. 2a, d). The annual runoff and sediment discharge were $\sim 54.82 \times 10^{8} \mathrm{~m}^{3}$ and $\sim 1.14 \times 10^{8} \mathrm{t}$, respectively, during 1997-2002. In particular, the lowest annual runoff of $18.6 \times 10^{8} \mathrm{~m}^{3}$ and sediment load $0.16 \times 10^{8} \mathrm{t}$ were observed in 1997, meanwhile the shoreline length shorten $2.33 \mathrm{~km}$ and area of $41.32 \mathrm{~km}^{2}$ land was lost (Figs. 2a, b and 4). From 2002 to 2006 , the total of $\sim 2.51 \times 10^{8} \mathrm{t}$ sediment discharged 

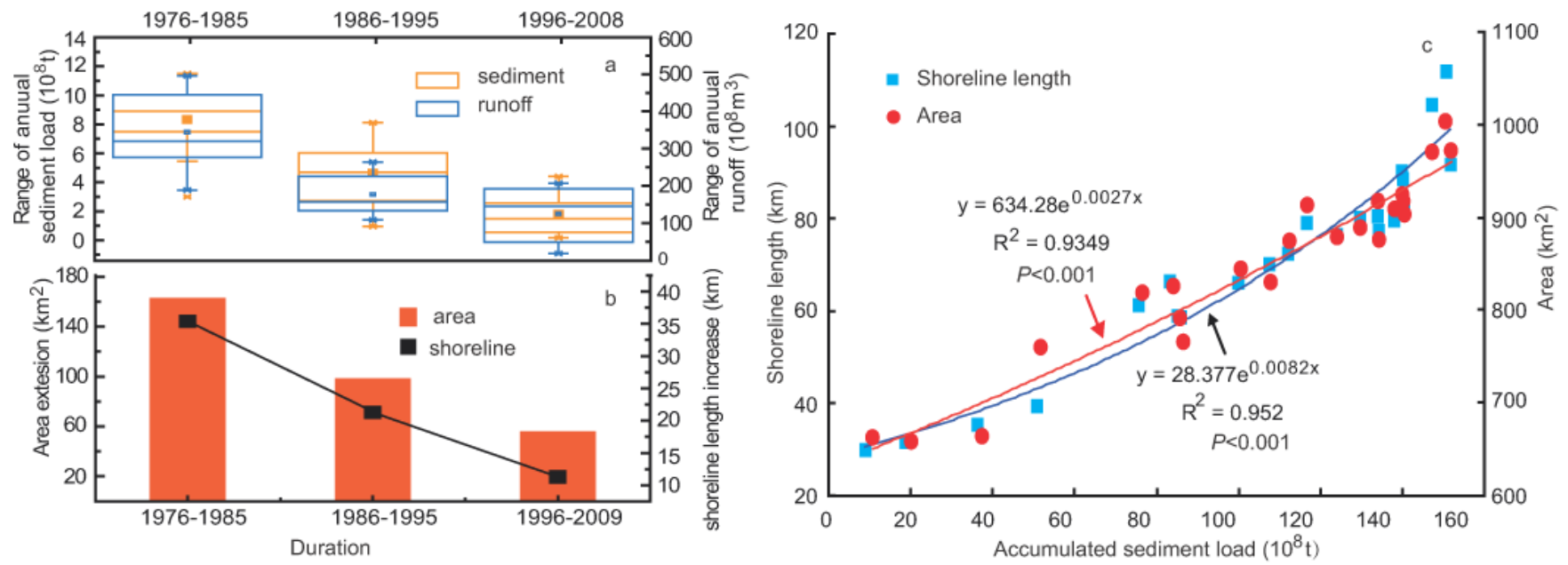

Fig. 6. The sediment load, runoff (a) and area extension (b) in different delta evolution stages, and relationships between the accumulated sediment and the shoreline length and area of Yellow River Delta (c).

to sea by 5 times of water and sediment regulations which carried out through the Xiaoliangdi reservoir, leading to the shoreline length and area of the Yellow River Delta extended $\sim 29.63 \mathrm{~km} \sim 99.48 \mathrm{~km}^{2}$. The shoreline and area of delta retreated obviously with dramatic reduction of runoff and sediment load. The annual water discharge and sediment load in the period of 1996-2008 were $124.92 \times 10^{8} \mathrm{~m}^{3}$ and $1.78 \times 10^{8} \mathrm{t}$, respectively, and annual shoreline length and area of 1996-2009 increased to $\sim 0.80 \mathrm{~km}$ and $\sim 3.94 \mathrm{~km}^{2}$, respectively (Fig. 6a, b).

The material basis of the Yellow River Delta evolution is sediment load conveyed by runoff (Cui et al., 2006; Yang et al., 2010). The Heavy-laden sediment along the Yellow River and associated coastal environmental managements have been discussed in the past century (Miao et al., 2010; Milliman and Meade, 1983; Qian et al., 1993). The positive relation of area extension and discharge of runoff and sediment in different evolution period of Yellow River Delta was found by several studies (Cui et al., 2006) (Liu et al., 2001). Huang and Fan (2004) found a significant linear relationship between extension of Qingshuigou channel and logarithm value of the accumulated sediment load during 1976-1996. In agreement with those findings, our analysis results showed that there exist significant exponential relationships between the accumulated sediment load and extensions of shoreline length and the area during the evolution of the modern Yellow River Delta (Fig. 6c). The total accumulated sediment load was $\sim 152 \times 10^{8} \mathrm{t}$, resulting in $\sim 308.81 \mathrm{~km}^{2}$ new-born land generated in the duration of 1976-2008.

\section{Conclusions}

The present study showed that changes of both runoff and sediment load in the Yellow River were downward trend with time during the 1976 to the 2008 (Fig. 2a, b) due mainly to climate change and human being activities including water diversion, soil and water conservation practices and water conservancy project in the upstream area (Ding and Pan, 2007; Huang and Fan, 2004; Peng and Chen, 2009; Qian et al., 1993; Wang et al., 2006; Xu and Sun, 2003). This reduction directly affected the evolution of shoreline and change of area of the Yellow River Delta (Fig. 6). In particular, increased seasonal channel dry-ups after 1990 (Fig. 2d) made net negative increases of land area occurred (Figs. 4 and 5), indicating runoff and sediment load close related human being activities are two key factors which controls the evolution of the Yellow River delta in recent decades.

Acknowledgements. We are grateful for support from the Knowledge Innovation Program of the CAS (Grant \# kzcx2-yw-223; kzcx2-yw-359); National Natural Science Fundation for Distinguished Young Scholar of Shandong Province (No. JQ201114); the CAS Strategic Priority Research Program (XDA05020503); The National Commonweal (Agricultural) research project (200903001); the CAS/SAFEA international partnership program for creation research team; the National Natural Science Foundation of China (40873062); the 100 Talents Program of the Chinese Academy of Sciences and the Science and Technology Planning Program of Shandong Province (No. 2008GG20005006, 2008GG3NS07005); Project of National Science \& Technology Pillar Program in "12th Five Year" period (2011BAC02B01) and Cooperative Project between the CAS and Local Authorities (Y12B011041). We thank Yellow River Delta Ecology Research Station of Coastal Wetland, CAS, with the help of field work. Four anonymous referees are thanked for constructive comments and suggestions, which were helpful for us in improving our manuscript.

The service charges for this open access publication have been covered by the Max Planck Society. 
Edited by: J. Yu

\section{References}

Bobrovitskaya, N. N., Kokorev, A. V., and Lemeshko, N. A.: Regional patterns in recent trends in sediment yields of Eurasian and Siberian rivers, Global Planet. Change, 39, 127-146, 2003.

Cai, D. L., Shi, X. F., Zhou, W. J., Liu, W. G., Zhang, S. F., Cao, Y. N., and Han, Y. B.: Sources and transportation of suspended matter and sediment in the southern Yellow Sea: Evidence from stable carbon isotopes, Chinese Sci. Bull., 48, 21-29, 2003.

Chen, J. Y.: The impact of sea level rise on China's coastal areas and its disaster hazard evaluation, J. Coast. Res., 13, 925-930, 1997.

Chen, Z. Y., Li, J. F., Shen, H. T., and Wang, Z. H.: Yangtze River of China: historical analysis of discharge variability and sediment flux, Geomorphology, 41, 77-91, 2001a.

Chen, Z. Y., Lu, L. Z., and Gupta, A.: The Yangtze River: an introduction, Geomorphology, 41, 73-75, 2001b.

Cui, B., Chang, X., Chen, Y., Dong, Q., and Li, W.: The impact of hydrological characteristics of the Yellow River coastline changes in the Yellow River Delta, J. Nat. Resour., 21, 957-964, 2006.

Cui, B. S., Tang, N., Zhao, X. S., and Bai, J. H.: A managementoriented valuation method to determine ecological water requirement for wetlands in the Yellow River Delta of China, J. Nat. Conserv., 17, 129-141, 2009.

Ding, Y. and Pan, S.: Evolutionary characteristics of runoff into the sea of the Huanghe river and their causes in recent 50 years, Quaternary Sci., 27, 709-717, 2007.

Fan, H., Huang, H. J., Zeng, T. Q., and Wang, K. R.: River mouth bar formation, riverbed aggradation and channel migration in the modern Huanghe (Yellow) River delta, China, Geomorphology, 74, 124-136, 2006.

Fan, Y., Zhang, S., Hou, C., and Zhang, L.: Study on Method of Coastline Extraction from Remote Sensing - Taking Yellow River Mouth Reach and Diaokou Reach of Yellow River Delta Area as an Example, Remote Sensing Inform., 0, 67-70, 2009.

Fan, Y. G., Li, R. H., and Zhang, S. Q.: Study on geographical information model of coastal erosion of Feiyan beach oil field of Yellow River delta, J. China Univer. of Geosci., 18, 76-78, 2007.

He, Q., Cui, B., Zhao, X., Fu, H., Xiong, X., and Feng, G.: Vegetation distribution patterns to the gradients of water depth and soil salinity in wetlands of Yellow River delta, china, Wetland Sci., 5, 208-214, 2007.

Huang, H. and Fan, H.: Monitoring changes of nearshore zones in the Huanghe (Yellow River) delta since 1976, Oceanologia Et Limnologia Sinica, 35, 306-314, 2004.

Huang, H. and Li, C.: Application of landsat images to the studies of the shoreline changes of the Huanghe River Delta, Marine Geol. Quaternary Geol., 14, 29-37, 1994.

Huang, H. and Li, F.: Conception model of land ocean interaction in the coast zone of the Yellow River delta, Adv. Earth Sci., 19, 808-816, 2004.

Lavery, P., Pattiaratchi, C., Wyllie, A., and Hick, P.: Water-Quality Monitoring in Estuarine Waters Using the Landsat Thematic Mapper, Remote Sens. Environ., 46, 268-280, 1993.

Li, G. S., Xue, X. H., Liu, Y., Wang, H. L., and Liao, H. P.: Diagnostic experiments for transport mechanisms of suspended sediment discharged from the Yellow River in the Bohai Sea, J. Geograph. Sci., 20, 49-63, 2010.

Li, S. N., Wang, G. X., Deng, W., Hu, Y. M., and Hu, W. W.: Influence of hydrology process on wetland landscape pattern: A case study in the Yellow River Delta, Ecol. Eng., 35, 1719-1726, 2009.

Liu, C. and Cheng, L.: Analysis on runoff series with special reference to drying up courses of lower Huanghe River, Acta Geograph. Sinica, 55, 257-265, 2000.

Liu, J., Saito, Y., Kong, X. H., Wang, H., and Zhao, L.: Geochemical characteristics of sediment as indicators of post-glacial environmental changes off the Shandong Peninsula in the Yellow Sea, Cont. Shelf Res., 29, 846-855, 2009.

Liu, J. G., Li, A. C., and Chen, M. H.: Environmental evolution and impact of the Yellow River sediments on deposition in the Bohai Sea during the last deglaciation, J. Asian Earth Sci., 38, 26-33, 2010 .

Liu, S., Li, C., Ding, J., Li, X., and Ivanov, V. V.: The rough balance of progradation and erosion of the Yellow River delta and its geological meaning, Marine Geol. Quaternary Geol., 21, 14-18, 2001.

Miao, C. Y., Ni, J. R., and Borthwick, A. G. L.: Recent changes of water discharge and sediment load in the Yellow River basin, China, Prog. Phys. Geog., 34, 541-561, 2010.

Milliman, J. D. and Meade, R. H.: World-Wide Delivery of River Sediment to the Oceans, J. Geol., 91, 1-21, 1983.

Milliman, J. D. and Syvitski, J. P. M.: Geomorphic Tectonic Control of Sediment Discharge to the Ocean - the Importance of Small Mountainous Rivers, J. Geol., 100, 525-544, 1992.

Peng, J. and Chen, S.: The variation process of water and sediment and Its effect on the Yellow River Delta over the six decades, Acta Geograph. Sinica, 64, 1353-1362, 2009.

Peng, J. and Chen, S. L.: Response of delta sedimentary system to variation of water and sediment in the Yellow River over past six decades, J. Geograph. Sci., 20, 613-627, 2010.

Qian, N. and Zhou, W.: Evolution of Riverbed in Lower Reaches of the Yellow River, Science Press, Beijing, 1965.

Qian, Y., Ye, Q., and Zhou, W.: Fluctuation of water and sediment discharge and riverbed evolution in the main channel of the Huanghe River, China Building Material Industry Press, Beijin, 1993.

Qiao, S. Q., Shi, X. F., Zhu, A. M., Liu, Y. G., Bi, N. S., Fang, X. S., and Yang, G.: Distribution and transport of suspended sediments off the Yellow River (Huanghe) mouth and the nearby Bohai Sea, Estuar. Coast. Shelf. S., 86, 337-344, 2010.

Serra, P., Pons, X., and Sauri, D.: Post-classification change detection with data from different sensors: some accuracy considerations, Int. J. Remote Sens., 24, 3311-3340, 2003.

Song, C., Liu, G., Liu, Q., Cao, M., and Huang, C.: Distribution patterns of plant communities in the Yellow River Delta and related affecting factors, Chin. J. Ecol., 27, 2042-2048, 2008.

Vorosmarty, C. J., Meybeck, M., Fekete, B., Sharma, K., Green, P., and Syvitski, J. P. M.: Anthropogenic sediment retention: major global impact from registered river impoundments, Global Planet. Change, 39, 169-190, 2003.

Walling, D. E. and Fang, D.: Recent trends in the suspended sediment loads of the world's rivers, Global Planet. Change, 39, 111126, 2003.

Wang, C., Cao, W., and Zhang, S.: Tidal current and its sediment 
transport capacity in Yellow River Estuary, J. Hydraul. Eng., 39, 1256-1262, 2008.

Wang, H. J., Yang, Z. S., Saito, Y., Liu, J. P., and Sun, X. X.: Interannual and seasonal variation of the Huanghe (Yellow River) water discharge over the past 50 years: Connections to impacts from ENSO events and dams, Global Planet. Change, 50, 212225, 2006

Wang, H. J., Yang, Z. S., Saito, Y., Liu, J. P., Sun, X. X., and Wang, Y.: Stepwise decreases of the Huanghe (Yellow River) sediment load (1950-2005): Impacts of climate change and human activities, Global Planet. Change, 57, 331-354, 2007.

Wang, Y. and Aubrey, D. G.: The Characteristics of the China Coastline, Cont. Shelf Res., 7, 329-349, 1987.

Wang, Z. Y. and Liang, Z. Y.: Dynamic characteristics of the Yellow River mouth, Earth Surf. Proc. Land., 25, 765-782, 2000.

$\mathrm{Xu}, \mathrm{J}$. and Sun, J.: Influence of precipitation and human activities on water fluxes from the Yellow River into the sea in the past 50 years, Adv. Water Sci., 14, 690-695, 2003.

$\mathrm{Xu}, \mathrm{X}$. G., Lin, H. P., and Fu, Z. Y.: Probe into the method of regional ecological risk assessment - a case study of wetland in the Yellow River Delta in China, J. Environ. Manage., 70, 253262,2004
Xue, C.: Historical changes in the Yellow River delta, China, Mar. Geol., 113, 321-330, 1993.

Yang, M., Liu, S., Sun, T., Cui, B., and Zhao, X.: Landscape change and its spatial heterogeneity in Yellow River Delta based on boundary characteristics, Chin. J. Ecol., 27, 1149-1155, 2008

Yang, W., Chen, S., Gu, G., and Chen, X.: Accretion and erosion characteristics of Qingshuigou Lobe of the Yellow River Delta in the near future, Marine Sci. Bull., 29, 40-51, 2010.

Yang, X., Damen, M. C. J., and Van Zuidam, R. A.: Use of thematic mapper imagery with a geographic information system for geomorphic mapping in a large deltaic lowland environment, Int. J. Remote Sens., 20, 659-681, 1999.

Yu, J., Chen, X., Sun, Z., Xie, W., Mao, P., Wu, C., Dong, H., Mu, X., Li, Y., Guan, B., and Shan, K.: The spatial distribution characteristics of soil nutrients in new-born coastal wetland in Yellow River delta, Acta Sci. Circum., 30, 855-861, 2010.

Zong, X., Liu, G., Qiao, Y., and Lin, S.: Study on dynamic changes of wetland landscape pattern in Yellow River Delta, Geo-Inform. Sci., 11, 91-97, 2009. 